\title{
Characteristics of Growth and Physiological Changes during Cold Treatment in Dormant Hanabusaya asiatica
}

\author{
Ho-Sun Lee, Dong-Lim Yoo ${ }^{1 * *}$, Seung-Yeol Ryu ${ }^{1}$, Jeong-Suk Sung, Hyung-Jin Baek, \\ Young-Yi Lee and Sok-Young Lee* \\ National Agrobiodiversity Center, National Academy of Agricultural Science, RDA. Suwon 441-717, Korea \\ ${ }^{1}$ Highland Agriculture Research Center, National Institute of Crop Science, RDA, Pyeongchamg 232-954, Korea
}

\begin{abstract}
This experiment was carried out to investigate the appropriate chilling requirements for breaking dormancy by treating the dormant plant of Hanabusaya asiatica with low temperature $\left(4^{\circ} \mathrm{C}\right)$ for different time periods. The rates of sprouting and flowering were higher with longer treatment periods at low temperature. In addition, the growth and flowering of the plant were better when it was potted after treatment at a low temperature for 90 days. The abscisic acid levels and polyphenoloxidase activity of the dormant plant increased during the low temperature treatment, reached a climax 90 days and decreased thereafter. The catalase activity was the lowest after the low temperature treatment for 90 days and increased subsequently. The peroxidase activity increased and showed a sharp rise after the low temperature treatment for more than 90 days. Considering the physiological activities of the enzymes, the changes in the abscisic acid levels, and the characteristics of growth and flowering after sprouting of the plant, the appropriate cold periods required for breaking dormancy could be 90 days.
\end{abstract}

Key words - Abscisic acid, Breaking dormancy, Enzyme activity, Year round flowering

\section{Introduction}

Hanabusaya asiatica (H. asiatica) is endemic to Korea and grows wildly with a bell-shaped flower of light violet color, a high ornamental quality, and a relatively long flowering period (Cho et al., 2001; Yoo et al., 2000). It is necessary to investigate the physiology of breaking dormancy in order to develop optimal cultivation techniques to produce as a viable commercial crop.

Plants develop dormancy to overcome long periods of unfavorable growing conditions such as cold winter. In dormant seeds or organs, no visible growth occurs, even when the growing conditions are favorable. The environmental conditions during the dormancy period trigger the developmental processes, which leads to the dormancy breaking. In seeds or organs, the resumption of growth coincides with, for example, water uptake (Bewley, 1997), the breakdown of reserves (Jabcobsen et al., 1995) or changes in the activation of enzymes and hormones.

Low temperatures of $1-10^{\circ} \mathrm{C}$ release from bud dormancy in the flora of the temperate zone (Bewley, 1997). It has been proposed that the physiological responses to low temperature during dormancy is detectable by the decrease in abscisic acid (ABA) levels (Xu et al., 2006), and changes in the carbohydrate content (Cappiello and Kling, 1994) and the activities of related enzymes (Wang et al. 1991). The Activity in dormancy breaking was accompanied by noticeable changes in the activities of antioxidant enzymes, e.g., peroxidase (Szecsko et al., 2002), catalase (Nir et al., 1993; Scalabrelli et al., 1991) and polyphenoleoxidase (PPO) (Wang et al., 1991).

Our aim was to identify the appropriate duration of low temperature that is needed to break dormancy of $H$. asiatica by investigating the changes in the activities of related enzymes and ABA levels, and the responses in growth and flowering in Hanabusaya when subjected to cold treatment.

*Corresponding author. E-mail : 1sy007@korea.kr, yd15901@korea.kr 


\section{Materials and Methods}

\section{Plant material and cold treatment}

Seeds of $H$. asiatica collected from Odae Mt. (main habitat in Korea) were germinated on filter paper (Whatmann No. 2) in a petri dish containing distilled water and the seedlings were planted in a pot containing 1:1:1 (v:v:v) loamy soil, leaf mould and sand, and then grown in a greenhouse for three years.

The roots obtained from plants having shriveled leaves and flowers by the cold weather were packed in moist peat with $60 \%$ relative humidity and then stored in refrigerator maintained at $4{ }^{\circ} \mathrm{C}$ for $0,30,60,90$, and 120 days, respectively. The roots treated with cold temperatures were planted in pot (1,300 mL volume) containing 1:1:1 (v:v:v) loamy soil, leaf mould, and sand and then grown in a greenhouse. The environmental conditions in the greenhouse were $60 \sim 70 \%$ humidity, $20 \pm 5^{\circ} \mathrm{C}$ temperature, and natural light absorbed from greenhouse. Control samples were defined as the roots which did not be treated with cold temperature ( 0 day).

\section{Measurement of growth and flowering}

The number of days to sprouting and flowering were calculated the days from the date of planting to the first date of showing sprout and flower. The rate of sprouting and flowering were calculated the percentage of sprouting and flowering plants to total same cold treated plants. The length of shoot was assessed the longest shoot and the number of leaves being longer than $0.5 \mathrm{~cm}$ on 120 days after planting. The number of flowers were recorded the total number of flowers flowered for 120 days after planting.

\section{Assay of abscisic acid and enzyme activities}

ABA extraction and enzyme activity assay were done with roots finished storage for relatively storage periods. The extraction of ABA was processed as described by Walton (1980). For each sample, approximately $5 \mathrm{~g}$ fresh weight of stored root was homogenized in liquid $\mathrm{N}_{2}$. Then, $200 \mathrm{~mL}$ of $80 \%$ methanol was added together with $0.25 \mathrm{~g}$ of ascorbic acid to prevent oxidation reactions during the extraction. The homogenate was stirred overnight at $4^{\circ} \mathrm{C}$. The insoluble material was removed first by centrifugation at $18,000 \mathrm{~g}$ for
$30 \mathrm{~min}$ and then by filtration with a no. 4 glass filter. The aqueous methanol was evaporated under reduced pressure at $37^{\circ} \mathrm{C}$. The residue was adjusted to $\mathrm{pH} 3.0$ with $1 \mathrm{~N} \mathrm{HCl}$. The sample was washed with ethyl acetate (4 times $80 \mathrm{ml}$ ) to remove lipids, fats, pigments, etc. The aqueous ethyl acetate was evaporated under reduced pressure at $37^{\circ} \mathrm{C}$. The residue was added $2 \%$ sodium bicarbonate to leave the neutral compounds in ethyl acetate. Then the sodium bicarbonate solution was partitioned against ethyl acetate and ethyl acetate was evaporated under reduced pressure at $37^{\circ} \mathrm{C}$. The residue was dissolved in I $\mathrm{ml}$ of methanol. This extract was used for quantification of ABA by Phytodetek ABA detection kit (Agdia incorporated, catalog No. PDK 09347).

For the analysis of enzyme activity, $1 \mathrm{~g}$ of root was weighed and ground immediately with a mortar and pestle in liquid nitrogen and added $5 \mathrm{ml} 0.1 \mathrm{M}$ sodium phosphate buffer ( $\mathrm{pH}$ 7.2). The resulting macerate was centrifuged at $10,000 \times \mathrm{g}$ for $30 \mathrm{~min}$. at $4{ }^{\circ} \mathrm{C}$. The supernatant was used for the analysis of enzyme activity. Peroxidase activity was measured by following changes in the absorbance at $500 \mathrm{~nm}$ in $2.9 \mathrm{ml}$ reaction mixture containing $235 \mathrm{ml} 0.1 \mathrm{M}$ acetate buffer ( $\mathrm{pH} 5.2$ ), $10 \mathrm{ml} 1 \% \mathrm{H}_{2} \mathrm{O}_{2}$, and $0.5 \mathrm{ml}$ guaiacol plus $0.1 \mathrm{ml}$ enzyme extract (Kar and Mishra, 1976). Catalase activity of the extract was measured spectrophotometrically by monitoring the decrease in absorbance at $240 \mathrm{~nm}$ in $0.1 \mathrm{M}$ phosphate buffer ( $\mathrm{pH}$ 7.0) containing $1.0 \% \mathrm{H}_{2} \mathrm{O}_{2}$ (Puntararulo et al., 1988). Polyphenoloxidase activity was measured by following the increase in the absorbance at $420 \mathrm{~nm}$ in $0.2 \mathrm{ml}$ $0.2 \mathrm{M}$ catechol, $2.0 \mathrm{ml} 0.5 \mathrm{M}$ potassium phosphate buffer (pH 7.2), and $0.3 \mathrm{ml}$ enzyme extract (Flurkey and Jen, 1978). Each assay was run 3 times and the specific activities of enzymes were calculated to unit $\cdot \mathrm{mg}^{-1} \operatorname{protein}^{-1} \cdot \mathrm{min}^{-1}$.

Duncan's multiple range test $(\mathrm{p}=0.05)$ was calculated as statistical analysis to evaluate the responses of growth and flowering. The results of the enzyme activity data are the means of five measurements.

\section{Results and Discussion}

\section{Effect of cold treatment duration on growth and flowering}

The effects of the duration of cold treatment at $4{ }^{\circ} \mathrm{C}$ on the characteristics of growth and flowering are presented in 
Table 1. Characteristics of sprouting and flowering in $H$. asiatica after the cold treatment for 0, 30, 60, 90 and 120 days.

\begin{tabular}{ccccc}
\hline \hline Period of cold treatment (days) & Days to sprouting & Sprouting Percentage (\%) & Days to flowering & Flowering Percentage (\%) \\
\hline 0 & No sprouting & 0.0 & No flowering & 0.0 \\
30 & $14.5 \mathrm{a}^{\mathrm{z}}$ & 73.0 & $152.1 \mathrm{a}$ & 50.3 \\
60 & $9.4 \mathrm{~b}$ & 72.0 & $123.3 \mathrm{~b}$ & 85.5 \\
90 & $9.6 \mathrm{~b}$ & 82.4 & $121.2 \mathrm{~b}$ & 95.2 \\
120 & $9.5 \mathrm{~b}$ & 100.0 & $116.5 \mathrm{~b}$ & 100.0 \\
\hline
\end{tabular}

${ }^{\mathrm{z}}$ Means in a columns were separated by Duncan's multiple range test at $\mathrm{p}=0.05$.

Table 1 and Fig. 1. The control group did not sprout and flower, whereas the cold-treated plants sprouted and flowered. The longer the periods of cold treatment, the shorter the time to sprouting and flowering was. The plants treated for 120 days showed $100 \%$ sprouting and flowering. The period until sprouting after cold treatment for 30 days was the longest. However, those after different cold treatments were similar. The sprouting percentage of cold-treated plants was significantly enhanced by the duration of the cold treatment at $4^{\circ} \mathrm{C} .100 \%$ sprouting occurred after cold treatment for 120 days. Plants treated for 90 days had a sprouting rate of $82.4 \%$. The height of the plants that were treated with cold temperatures for 30 to 90 days ranged from 8.6 to $16.6 \mathrm{~cm}$. The cold treatment for 120 days resulted in the highest plant height. The results on the number of leaves and flowers were similar to that of the plant height. The cold treatment for 120 days resulted in the highest number of leaves and flowers.

H. asiatica normally flowers between August and September at its natural habitat. It goes into dormancy during the cold season noticeable by changes in the color and abscission of the leaves. When the temperature rises in the following spring, sprouts appear leading to formation of leaves and flowers. Dormant plants do not show external morphological changes or stop growing. However, many physiological and morphological events occur internally, e.g. root initiation (Le Nard and De Hertogh, 1993). In plants that are dormant in winter, dormancy was broken by proper periods at low temperature (approximately $4^{\circ} \mathrm{C}$ ). Considering the responses of cold treatment to sprouting and flowering in $H$. asiatica, dormancy began to break after a cold treatment of at least 30 days and the percentage of sprouting and flowering increased dramatically when the plants were treated with cold for 90 days. The dormancy was completely broken by the cold

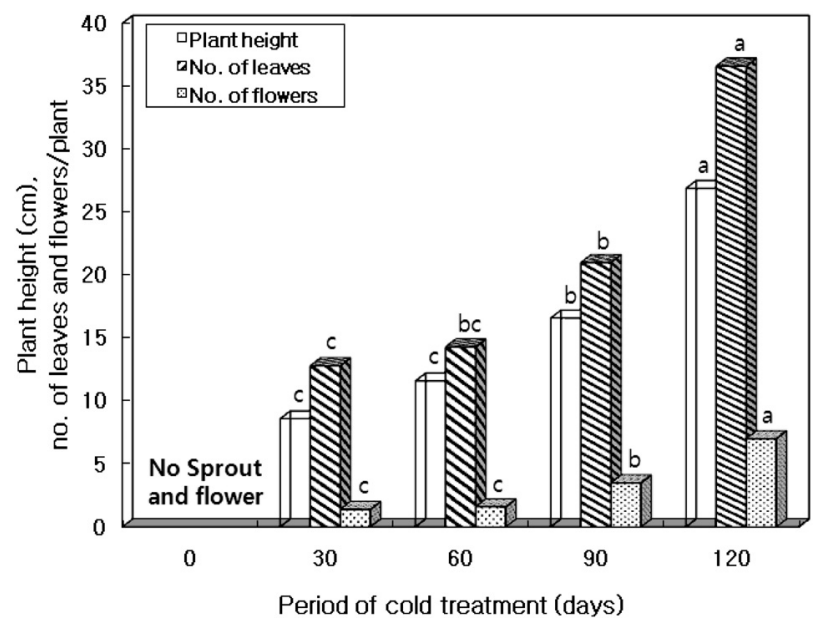

Fig. 1. Characteristics of growth and flowering of $H$. asiatica affected by the duration of cold treatment. Letters above indicate the mean separation within treatments by Duncan's multiple range test at $5 \%$ level.

treatment for 120 days. The results indicate that the internal dormancy of $H$. asiatica could be broken by a minimum of 90 days at $4{ }^{\circ} \mathrm{C}$.

The percentage of sprouting was $72-73 \%$ after the coldtreatment for 30 and 60 days in also H. asiatica. The cold treated plants for 30 and 60 day had the short plant height, lower number of leaves and flowers. Therefore, these results indicated that the long external dormancy is induced by unfavorable conditions, such as low temperature after internal dormancy, even though the requirement of a low temperature for breaking the internal dormancy is relatively short. When H. asiatica is grown in a warm green house after a cold treatment for a minimum of 90 days immediately after it lost its leaves in October, new flowers could be seen in winter.

In Gypsophilla and Chrysanthemum, undesirable chilled exposure induced to rosette-like growth, disqualified flowers 


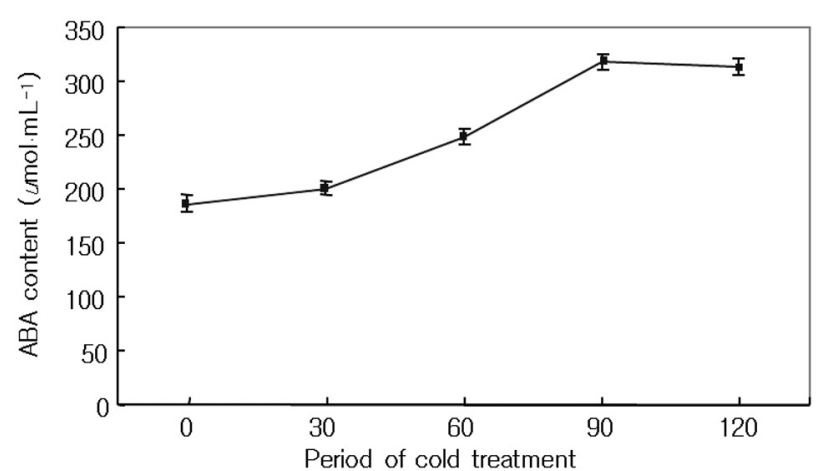

Fig. 2. Changes of ABA content of root affected by the duration of cold treatment in H. asiatica. Vertical bars indicate standard error.

or flower abortion (Bernier et al., 1981). Chilling at $5^{\circ} \mathrm{C}$ for three-four weeks in Primula sieboldii and Disporum smilacinum were the most effective treatment for breaking the dormancy and promoting uniform sprout emergence (Suh et al., 2006). Pulsatilla koreana Nakai (Ha et al., 1988), Paeonia and German iris (Bernier et al. 1981) treated with sub-optimal cold treatment resulted in an increased blindness and malformation. In order to regulate the flowering time of native plants, such as Convallatia keiskei (Yoon and Lee, 1988) and Bletilla striata (Yoo et al., 2001), for cultivation as floricultural plants, cold treatment is the best way for breaking the internal dormancy.

\section{Changes in ABA and the activities of antioxidant enzymes according to cold treatment}

The ABA contents gradually increased until up to 90 days after cold treatment and, slightly decreased after a cold treatment at $4^{\circ} \mathrm{C}$ for 120 days (Fig. 2). The ABA content appears to act as the dormancy-inducing hormone, as indicated by an observed correlation between levels of endogenous ABA and the physiological state (Taiz and Zeiger, 1991). Dry dormant seeds usually contain higher concentration of ABA than non-dormant seeds. It appears that the hormonal balance between ABA and GA, controls the transition from dormancy to sprouting in the case of bud dormancy (Taiz and Zeiger, 1991). The results shown in the present work indicate that ABA level was increased during internal dormancy, until 90 days of cold treatment, and then decreased after breaking the internal dormancy, at the cold treatment for 120 days. The

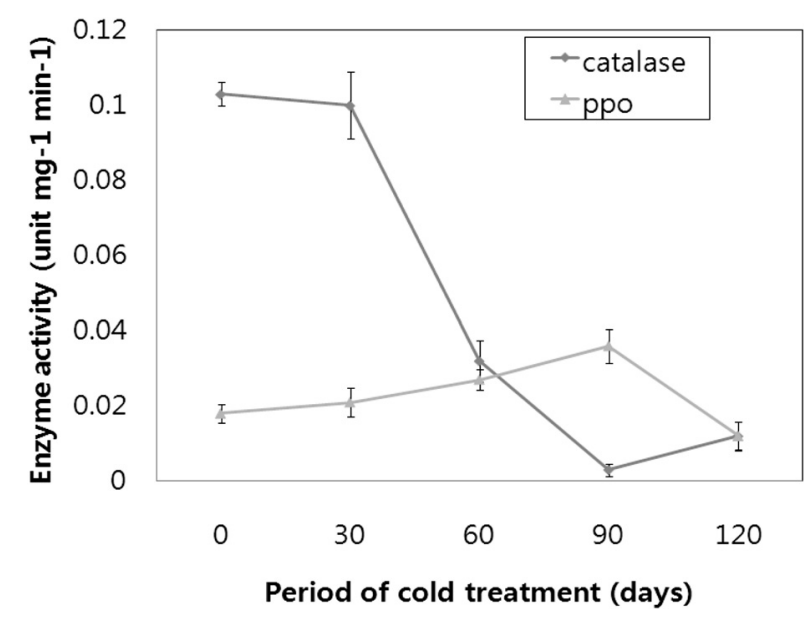

Fig. 3. Changes of catalase and polyphenoloxidase (PPO) activities of root affected by the duration of cold treatment in $H$. asiatica. Vertical bars indicate standard error.

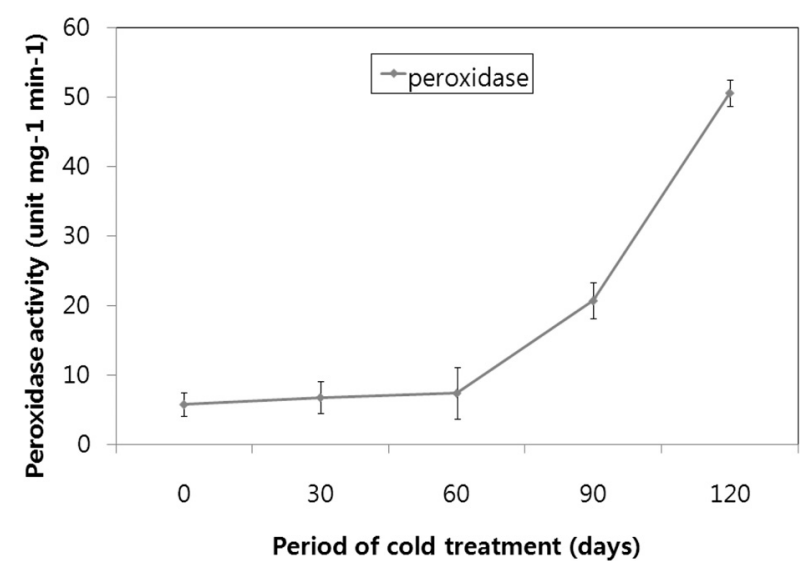

Fig. 4. Changes of peroxidase activity of root affected by the duration of cold treatment in $H$. asiatica. Vertical bars indicate standard error.

results of this study agree with those presented by Cappiello and Kling (1994) from the study of Cornus sericea. Both studies showed gradually increasing levels of ABA during dormancy followed by a slight decrease of ABA levels before break dormancy. The rise in ABA levels before bud break and the responses to growth and flowering according to cold treatment were similar to those reported in Megaleranthis saniculifolia (Lee et al. (2003).

The activities of catalase, PPO, and peroxidase were monitored after 30,60, 90, and 120 days of cold treatment at $4{ }^{\circ} \mathrm{C}$. There was negative relationship between the catalase activities and the PPO activities during the cold treatment (F 
ig. 3). After a dramatic decrease of the catalase activity until 90 days, it was recovered after a cold treatment for 120 days. The activity of PPO gradually increased until 90 days of cold treatment, and decreased after the 120 days. Peroxidase activities gradually increased until 60 days of cold treatment and significantly increased after 90 days of cold treatment (Fig. 4).

Peroxidase, catalase and PPO are antioxidant enzymes and the essential criterion of physiological activity (Puntararulo, 1988). The starting point of dormancy, the end of internal dormancy and the beginning of external dormancy are not clearly defined. The changes in enzyme activities seem to be an indicator for the end of the dormancy and the beginning of growth as described by many authors (Bassuk et al., 1981; Marquat et al., 1999). Schaefer (1983) found in grapevine that the peroxidase activity in the roots, shoots and trunk increased in autumn, was the highest in December, and decreased afterward. The catalase activity showed a similar pattern. It was highest during the middle of dormancy, and decreased profoundly towards the end of dormancy (Scalabrelli et al., 1991). The cold treatment for 90 days was the turning point for the level of activity of catalase and PPO and resulted in a noticeable rise in the peroxidase activity. These results indicated that the cold treatments for more than 90 days might be an unfavorable condition for breaking dormancy. Therefore, the significant changes in the activities of catalase and PPO occurred after 120 days of cold treatment, when the plant was again capable to respond to cold-stress, and the external dormancy is induced.

In the present work, the minimum duration of cold treatment in order to break the internal dormancy could be 90 days as indicated by the observed correlation between the changes of ABA contents, the changes of the activities of antioxidant enzymes such as catalase, peroxidase, and PPO and the responses of growth and flowering according to duration of cold treatment. The changes in ABA level and activities of antioxidant enzymes can be an indicator for determining the end of the internal dormancy when important endogenous changes occur.

\section{Acknowledgement}

This research was funded in part by the R \& D Promotion Center for Agriculture and Forestry in Korea.

\section{Literature Cited}

Bassuk, N.L. and B.H. Howard. 1981. A positive correlation between endogenous root-inducing cofactor activity in vacuumextracted sap and seasonal changes in rooting of M26 winter apple cuttings. J. Hort. Sci. 4:301-312.

Bernier, G., J.M. Kinet and R.M. Sachs. 1981. The physiology of flowering. Vol. 1. CRC Press, FL. pp. 69-82.

Bewley, J.D. 1997. Seed germination and dormancy. The Plant Cell 9:1055-1066.

Cappiello, P.E. and G.J. Kling. 1994. Changes in growth regulator and carbohydrate levels in roots and shoot tips of Cornus sericea during cold storage and emergence from dormancy. J. American Soc. Hort. Sci. 119:785-788.

Cho, K.S., J.E. Jung, D.L. Yoo, S.Y. Ryu and Y.R. Yong. 2001. Effects of low temperature and $\mathrm{GA}_{3}$ treatment on the growth and flowering of Hanabusaya asiatica. J. Korean Soc. Hort. Sci. 42: 116-120 (in Korean).

Flurkey, W.H. and J.J. Jen. 1978. Peroxidase and polyphenol oxidase activities in developing peaches. Food Sci. 43: 1826-1829.

Ha, S.G., C.K. Chun and S.T. Choi. 1988. Studies on flower bud differentiation and forcing of Pulsatilla koreana. J. Korean Soc. Hort. Sci. 29:46-52 (in Korean).

Jabcobsen, J.V., F. Gubles and P.M. Chandler. 1995. Gibberellin action in germinated cereal grains. In Davies P.J. (eds.). Plant hormones: Physiology, Biochemistry and Molecular Biology. Kluwer Academic Pub., Dordrecht, Netherland. pp. 246-271.

Kar, M. and D. Mishra. 1976. Catalase, peroxidase, and polyphenol oxidase activities during rice leaf senescence. Plant Physiol. 57:315-319.

Lee, H.S., D.L. Yoo and S.Y. Ryu. 2003. Characteristics of growth, flowering, and activity changes of several enzymes of Megaleranthis saniculifolia by chilling. J. Korean Soc. Hort. Sci. 44:790-794 (in Korean). 
Le Nard M. and A.A. De Hertogh. 1993. Bulb growth and development and flowering. In De Hertogh A.A. and M. Le Nard (eds.). The Physiology of Flower Bulbs. Elsevier, Amsterdam, Netherland. pp. 29-43.

Marquat C. M., M. Vandamme, M. Gendrdraud and G. Petel. 1999. Dormancy in vegetative buds of peach: Relation between carbohydrate absorption potentials and carbohydrate concentration in the bud during dormancy and it release. Sci. Horti. 79: 151-162.

Nir, G., S. Lavee, S. Lavee and R. Goren. 1993. Metabolic changes during cyanamide induced dormancy release in grapevine. Acta Hort. 329: 271-274.

Puntararulo, S., R.A. Sanchez and A. Boveris. 1988. Hydrogen peroxide metabolism in soybean embryonic axis at the onset of germination. Plant Physiol. 86:626-630.

Scalabrelli, G., R. Viti and F. Cinelli. 1991. Changes in catalase activity and dormancy if apricot buds in response to chilling. Acta Hort. 293:267-274.

Schaefer H. 1983. Seasonal changes and probable importance of peroxidase activity in woody parts. Vitis 1: 1-8.

Suh, J.T., S.Y. Hong, D.L. Yoo, S.J. Kim, C.W. Nam and S.Y. Ryu. 2006. Effect of low temperature for the breaking dormancy of Primula sieboldii, P. modesta var. fauriae and Disporim smilacinum. J. Korean Plant Res. 19:45-49 (in Korean).
Szecsko, V., K. Hrotko and E. Stefanovits-Banyai. 2002. Seasonal variability in phenol content, peroxidase and polyphenoloxidase enzyme activity during the dormant season in plum rootstocks. Acta Bio. Szegediensis 46:211-212.

Taiz L. and E. Zeiger. 1998. Plant physiology. The Benjamin/ Cummings Publishing Co., Redwood City, CA. pp. 482-487

Walton, D.C. 1980. Biochemistry and physiology of abscisic acid. Annu. Rev. Plant Physiol. 31:453-489.

Wang, S.Y., H.J. Jiao and M. Faust. 1991. Changes in the activities of catalase, peroxidase, and polyphenol oxidase in apple buds during bud break induced by thidiazuron. J. Plant Growth Regul. 10:33-39.

Xu, R.Y., Y. Niimi and D.S. Han. 2006. Changes in endogenous abscisic acid and soluble sugars levels during dormancyrelease in bulbs of Lilium rebellum. Sci. Hort. 111:68-70.

Yoo, K.O., W.T. Lee and S.Y. Ryu. 2000. External morphology and numerical taxonomy of Hanabusaya asiatica populations in different habitats. J. Korean Plant Res. 13:80-88 (in Korean).

Yoo, Y.K., H.K. Kim and K.H. Choi. 2001. Regulation of growth and flowering by low temperature treatment in Bletilla striata. J. Korean Soc. Hort. Sci. 42:227-232 (in Korean).

Yoon, P.S. and J.S. Lee. 1998. The effect of temperature on the forcing and dormancy breaking of Convallaria keiskei Miq. J. Korean Soc. Hort. Sci. 39:74-78 (in Korean).

(Received 9 March 2011 ; Accepted 3 June 2011) 